\title{
Intimate partner violence, health behaviours, and chronic physical illness among South African women
}

\author{
Jesse D Gass, Dan J Stein, David R Williams, Soraya Seedat
}

Objectives. An association between intimate partner violence and adverse physical health outcomes and health-risk behaviours among women has been established, most scientific research having been conducted in the USA and other developed countries. There have been few studies in developing countries, including South Africa, which has one of the highest rates of intimate partner violence in the world. We therefore sought to study the association between physical intimate partner violence and physical health outcomes and behaviours among South African women.

Methods. Using data from the cross-sectional, nationally representative South African Stress and Health Study, we assessed exposure to intimate partner violence, health-risk behaviours, health-seeking behaviours and chronic physical illness among a sample of 1229 married and cohabiting women.

Results. The prevalence of reported violence was $31 \%$. This correlated with several health-risk behaviours (smoking, alcohol consumption, and use of non-medical sedatives, analgesics and cannabis) and health-seeking behaviours (recent visits to a medical doctor or healer). Intimate partner violence was not significantly associated with chronic physical illness, although rates of headache, heart attack and high blood pressure reached near-significance.

Conclusions. Partner violence against women is a significant public health problem in South Africa, associated with healthrisk behaviours and increased use of medical services. Public health programmes should incorporate interventions to mitigate the impact of violence on victims and reduce the risk of negative behavioural outcomes. Further investigation of the pathways between violence exposure and health behaviours is needed to inform the design of such programming.

S Afr Med J 2010; 100: 582-585.
Intimate partner violence (IPV) is a global public health problem that is increasingly cited as a risk factor for adverse physical and behavioural health outcomes among women. Characterised by behaviour within an intimate relationship that causes physical, psychological or sexual harm to a partner, ${ }^{1}$ IPV has reached globally epidemic proportions. The lifetime prevalence of experiencing IPV is estimated to be between $15 \%$ and $71 \%$ among women worldwide. ${ }^{2}$

Apart from an increased risk of injury and death, women who experience IPV have an increased probability of developing shortand long-term morbidity and adopting negative health behaviours. For example, in the USA abused women are more likely than nonabused women to report adverse physical health outcomes such as joint disease, asthma, heart disease, back problems, arthritis, sexually

Mailman School of Public Health, Columbia University, New York Jesse D Gass, MPH

Department of Psychiatry and Mental Health, University of Cape Town Dan J Stein, FRCPC, PhD, DPhil

Department of Society, Human Development and Health, Harvard School of Public Health, and Department of African and African American Studies, Harvard University, Cambridge, Massachusetts

David R Williams, MPH, $\mathrm{PhD}$

MRC Anxiety and Stress Disorders Unit, Department of Psychiatry, Stellenbosch University, Tygerberg, $W$ Cape

Soraya Seedat, MB ChB, FCPsych (SA), $\mathrm{PhD}$ transmitted infections, vaginal infections, digestive problems and poor overall health. ${ }^{3-5}$ Women with a history of IPV victimisation report increased rates of health risk behaviours, such as HIV risk factors, smoking, and alcohol and drug use. ${ }^{4,6-8}$ Estimates of abused women's use of health care services is conflicting; some found a nearly equivalent probability of $u^{8} e^{8}$ and others a decreased probability ${ }^{4}$ compared with non-abused women.

A study on domestic violence in nine developing countries ${ }^{9}$ also found increased rates of injury and adverse health outcomes among abused women. A 2008 World Health Organization (WHO) multicountry study on IPV and women's physical and mental health found a significant association between lifetime experience of IPV and selfreported poor health and specific health problems. ${ }^{10}$ Most countries included in these studies were low and middle income. However, studies in North America dominate the research on the health effects of partner violence, many of which rely on clinical samples. This research needs to be expanded to include population-based samples in developing countries.

In South Africa, which has among the highest rates of IPV in the world, violence has an extremely deleterious effect on women's health. Although prevalence estimates of IPV vary, rates are consistently high. A nationally representative study found a $19 \%$ lifetime prevalence of victimisation among female respondents, ${ }^{11}$ and a study on physical violence among South African men found that $27.5 \%$ reported perpetration in their current or most recent partnership. ${ }^{12}$ Earlier studies report similar estimates. ${ }^{13-17}$ IPV is a leading cause of morbidity and mortality for South African women. Over half of female homicide victims are killed by their intimate partners. ${ }^{18}$ Women with violent partners are at increased risk of HIV infection ${ }^{14,15}$ and health risk behaviours such as alcohol consumption. ${ }^{16}$

We sought to address the dearth of scientific data on the health effects of IPV among women in developing countries and to elucidate the health consequences of IPV in a setting with an unprecedented burden of morbidity and mortality due to interpersonal violence. Using data from a nationally representative, cross-sectional study, we investigated the association between exposure to IPV and health-risk 
behaviours, health-seeking behaviours, and chronic physical illness among a sample of 1229 married and cohabiting South African women.

\section{Methods \\ Sample and procedure}

We used data from the South African Stress and Health (SASH) study, ${ }^{19,20}$ a nationally representative psychiatric epidemiological survey of 4351 adult South Africans (aged $\geq 18$ years) living in households and hospital-based hostels, conducted between 2002 and 2004 as part of the WHO's World Mental Health Survey Initiative. The SASH sample was selected using a three-stage clustered area probability sample design: the first stage selected stratified primary sample areas based on the 2001 South African Census Enumeration Areas; the second sampled housing units within clusters selected within each Enumeration Area; and the third randomly selected one adult respondent in each sampled housing unit. Inclusion criteria determining sampling for this study were report of being currently married or in a cohabiting relationship, and response to the survey questions about health-risk behaviours, health-seeking behaviours, and chronic physical illness.

Data collection proceeded province by province with a cohort of 40 - 60 interviewers in each province. All SASH interviewers were trained in field research methods and the administration of the paper-andpencil version of the Composite International Diagnostic Interview used by the World Mental Health Survey Initiative. ${ }^{21}$ Surveys were administered in person during pre-scheduled appointments in one of seven languages: English, Afrikaans, Zulu, Xhosa, Northern Sotho, Southern Sotho and Tswana. Field interviewers made up to three attempts to contact each respondent, and the overall response rate was $85.5 \%$. All recruitment, consent and field procedures were approved by the Human Subjects Committees of the University of Michigan and Harvard Medical School. A single project assurance of compliance was obtained from the Medical University of South Africa (MEDUNSA), which was approved by the National Institute of Mental Health.

\section{Measurement}

Respondents were asked to refer to their current or most recent marriage or cohabiting relationship and how often, when they had a disagreement, their partner or spouse pushed, grabbed, shoved, threw something, slapped, or hit them (often, sometimes, rarely, never). Violence was defined as occurring often, sometimes, or rarely.

We examined three sets of risk factors: health-risk behaviours, health-seeking behaviours, and chronic physical illness. Analyses included current, past-year and lifetime measurements. Health-risk behaviours included current and lifetime tobacco use, current regular use (defined as drinking at least 12 drinks per year) and lifetime use of alcohol, past-year and lifetime non-medical use of medications (sedatives, stimulants, analgesics), and current and lifetime use of illicit drugs. Health-seeking behaviours included seeking stability in sexual relationships, taking precautions in sexual intercourse to prevent HIV/AIDS, and recent and lifetime AIDS tests. Remaining measures of health-seeking pertained to service use, specifically visits to a medical doctor, traditional healer or other health care professional in the past 12 months.

Twenty indicators of chronic physical illness were analysed. Respondents were asked whether they had experienced arthritis, back problems, headaches, chronic pain, allergies, stroke or heart attack in the past 12 months, and whether they had ever had heart disease, high blood pressure, asthma, tuberculosis, lung disease, malaria, diabetes, ulcer, thyroid disease, any neurological problem, HIV/ AIDS, epilepsy or cancer.

\section{Statistical analysis}

Statistical analyses used the Taylor linearisation method, assuming a with-replacement design, from the SUDAAN statistical package, version 10.0. ${ }^{22}$ Prevalence of health outcomes and behaviours was calculated and stratified by IPV experience. Logistic regression models included age, race, cohabitation, education, income, employment status and geographical location (rural v. urban) as covariates. Predictors were demographic factors and IPV victimisation, included in all the models without a stepwise regression. Dependent variables included health-risk behaviours, health-seeking behaviours and chronic physical illness, entered one at a time and adjusted for covariates, resulting in one logistic model for each outcome. Statistical significance was established using the Wald chi-square test with $\mathrm{p}<0.05$.

\section{Results}

Table I presents the results of adjusted logistic models predicting health-risk behaviours, health-seeking behaviours and physical illness. The sample comprised 1229 women; 31\% reported experiencing IPV in their most recent marriage or cohabiting relationship. IPV victimisation significantly positively correlated with several healthrisk behaviours. Compared with non-abused women, abused women were 1.7 times more likely to report ever smoking, 1.9 times more likely to report current smoking, nearly twice as likely to report ever drinking, and approximately 2.4 times more likely to report regular drinking and non-medical use of sedatives. IPV nearly doubled the likelihood of lifetime and past-year non-medical use of analgesics. Abused women were 3.8 times more likely than non-abused women to report ever using cannabis and 48 times more likely to report using cannabis in the past 12 months. Although originally included, use of cocaine was dropped as an outcome as its use was not reported by IPV victims.

Among health-seeking behaviours, IPV correlated with any pastyear visits to a medical doctor and traditional healer. Compared with non-abused women, women reporting IPV were 1.5 times more likely to have visited a doctor and nearly twice as likely to have visited a traditional healer in the past 12 months. Abused women were slightly more likely than non-abused women to report seeking stability in sexual relationships, taking precautions in sexual intercourse to prevent HIV/AIDS, and recent and lifetime AIDS tests, but these were not statistically significant. IPV was not significantly associated with any chronic physical illnesses, although rates of headache $(p=0.069)$, heart attack $(p=0.051)$ and high blood pressure $(p=0.080)$ reached near-significance.

\section{Discussion}

Consistent with previous research, women with a history of IPV had a significantly higher probability than non-abused women of exhibiting health-risk behaviours, including smoking, alcohol and cannabis use, and non-medical use of sedatives and analgesics. SASH studies found a significant association between domestic violence perpetration and all categories of psychiatric disorders, including substance use disorders. ${ }^{23}$ In South Africa, alcohol consumption in particular is significantly associated with IPV. ${ }^{16}$ In the USA female victims of IPV report higher rates of alcohol abuse/dependence, smoking and drug abuse than non-victims. ${ }^{4,6-8}$ Alcohol and substance abuse is a well-documented risk factor for violence; any comprehensive IPV intervention must therefore address these behaviours. ${ }^{1}$ Our findings raise the possibility of the reverse association, that IPV may be a risk factor for substance abuse. Although causality is difficult to establish, research has suggested that IPV precedes alcohol and substance abuse in most cases, supported by evidence that alcohol and substance use 


\begin{tabular}{|c|c|c|c|c|}
\hline Outcome & OR & LCI & UCI & $p$-value \\
\hline \multicolumn{5}{|l|}{ Health-risk behaviours } \\
\hline Ever smoker & 1.68 & 1.06 & 2.68 & 0.029 \\
\hline Current smoker & 1.90 & 1.09 & 3.30 & 0.024 \\
\hline Ever drinker & 1.89 & 1.30 & 2.75 & 0.001 \\
\hline Regular drinker & 2.37 & 1.28 & 4.41 & 0.007 \\
\hline Non-med sedative & 2.43 & 1.11 & 5.33 & 0.027 \\
\hline Non-med sedative, $12^{*}$ & 1.26 & 0.60 & 2.64 & 0.541 \\
\hline Non-med stimulant & 2.77 & 0.74 & 10.38 & 0.129 \\
\hline Non-med stimulant, 12 & 1.44 & 0.18 & 11.23 & 0.725 \\
\hline Non-med analgesic & 1.82 & 1.24 & 2.66 & 0.003 \\
\hline Non-med analgesic, 12 & 1.72 & 1.11 & 2.65 & 0.015 \\
\hline Cannabis use & 3.83 & 1.30 & 11.27 & 0.016 \\
\hline Cannabis use, 12 & 48.13 & 3.63 & 638.61 & 0.004 \\
\hline Other drug use & 0.77 & 0.11 & 5.51 & 0.795 \\
\hline \multicolumn{5}{|l|}{ Health-seeking behaviours } \\
\hline Partner stability & 0.95 & 0.64 & 1.42 & 0.815 \\
\hline Sexual precautions & 0.86 & 0.61 & 1.22 & 0.404 \\
\hline AIDS test & 1.18 & 0.77 & 1.81 & 0.433 \\
\hline AIDS test, 12 & 1.22 & 0.73 & 2.05 & 0.434 \\
\hline Any MD visit, 12 & 1.50 & 1.10 & 2.06 & 0.011 \\
\hline Any healer visit, 12 & 1.96 & 1.17 & 3.28 & 0.011 \\
\hline Any health visit, 12 & 1.36 & 0.93 & 1.97 & 0.108 \\
\hline \multicolumn{5}{|l|}{ Physical illness } \\
\hline Arthritis, 12 & 0.86 & 0.54 & 1.38 & 0.532 \\
\hline Back problems, 12 & 1.24 & 0.88 & 1.76 & 0.210 \\
\hline Headaches, 12 & 1.35 & 0.98 & 1.88 & 0.069 \\
\hline Chronic pain, 12 & 1.21 & 0.81 & 1.80 & 0.351 \\
\hline Allergies, 12 & 1.29 & 0.84 & 1.98 & 0.244 \\
\hline Stroke, 12 & 1.32 & 0.62 & 2.79 & 0.462 \\
\hline Heart attack, 12 & 1.82 & 1.00 & 3.32 & 0.051 \\
\hline Ever heart disease & 1.23 & 0.69 & 2.18 & 0.471 \\
\hline Ever high BP & 1.45 & 0.96 & 2.20 & 0.080 \\
\hline Ever asthma & 1.03 & 0.56 & 1.89 & 0.927 \\
\hline Ever tuberculosis & 0.66 & 0.26 & 1.67 & 0.374 \\
\hline Ever lung disease & 0.38 & 0.10 & 1.42 & 0.147 \\
\hline Ever malaria & 2.49 & 0.79 & 7.86 & 0.118 \\
\hline Ever diabetes & 1.36 & 0.67 & 2.75 & 0.384 \\
\hline Ever ulcer & 1.49 & 0.86 & 2.57 & 0.155 \\
\hline Ever thyroid disease & 2.00 & 0.73 & 5.48 & 0.175 \\
\hline Ever neurological problem & 1.62 & 0.51 & 5.14 & 0.409 \\
\hline Ever HIV/AIDS & 0.37 & 0.01 & 9.98 & 0.546 \\
\hline Ever epilepsy & 0.94 & 0.13 & 6.80 & 0.947 \\
\hline Ever cancer & 1.25 & 0.22 & 7.10 & 0.795 \\
\hline
\end{tabular}

are coping mechanisms for violent or stressful situations. ${ }^{8,24}$ These findings indicate that the relationship between IPV and risky health behaviours warrants further investigation and that substance abuse intervention should be a key component of violence prevention programmes.

Among health-seeking behaviours, abused women were more likely than non-abused women to report past-year visits to a medical doctor or traditional healer, supporting findings that IPV victims use a disproportionate share of health care services. ${ }^{5,24}$ Although we could not assess the specific reasons for women seeking health care, our findings, supported by prior research in this area, ${ }^{25}$ indicate that health care settings may serve as opportune contexts in which to screen and counsel women for IPV. These results introduce the possibility that behaviour may mediate the relationship between IPV and risk of physical illness. Further research is needed to determine whether, independent of violence exposure, health-risk behaviour may increase the probability of illness and health-seeking behaviour may decrease it.

We did not find a strong correlation between experiencing IPV and chronic physical illness, contrary to previous findings indicating that battered women have significantly higher rates of self-reported chronic health problems. However, several limitations preclude direct comparison of results. Variations in research methodology, including differences in operational definitions of IPV, sample inclusion criteria, data collection methods and barriers to disclosure, may account for the differences between results. It is particularly likely that inconsistencies in defining violence and variations in time frames significantly influence discrepancies in prevalence estimates. For instance, the vast majority of studies reviewed defined IPV as including sexual or psychological abuse in addition to physical violence. Had we also collected data on sexual and psychological abuse, it would have allowed for reporting on a wider range of violent behaviour, which may have increased the association with physical illness. Furthermore, assessing lifetime prevalence as many prior studies have done, as opposed to IPV within the current or most recent partnership, and including adults without a history of marriage or cohabitation can also alter levels of reported illness. Finally, most studies on this topic have been conducted in the USA and countries other than South Africa, and many have sampled clinical populations, which tend to have higher rates of illness than population-based samples.

Beyond issues pertaining to violence assessment and sample inclusion criteria, we were also unable to collect data on the dynamics of violence exposure, specifically its timing, frequency, context and severity. Self-report may have affected our rates of physical illness if women were unaware of health problems or misunderstood their diagnoses, or if health problems were undiagnosed. Knowledge of specific health conditions is also a function of access to and quality of medical care. As some of our respondents faced challenges in this regard, as is common in South Africa, it would affect their ability to report on specific health conditions. Furthermore, given the diversity of the sample population, language and/or cultural issues pertaining to terminology used for common physical illnesses may have influenced our results. The survey's brief section on physical health may have contributed to underestimating the true association between IPV and poor health outcomes, as repeated questions tend to reveal higher prevalence rates for abuse, perhaps making disclosure easier for the respondent. Data on the health behaviours of male partners were not included; studies have shown that a significant proportion of men who perpetrate violence also abuse substances, which could be a confounding variable. The study's cross-sectional design did not allow us to infer a causal relationship between IPV and each of the outcome variables. Finally, the study was subject to possible retrospective and social desirability biases, which may have contributed to underreporting of violence. However, the data collection instrument that was used assessed specific forms of physical violence based on modified items from the internationally validated Conflict-Tactics Scale in order to decrease such biases. ${ }^{26,27}$

\section{Conclusion}

Partner violence is predictive of health-risk behaviours and increased use of health care services among victimised women, indicating that 
substance abuse intervention should be a key component of violence intervention programming and that health care settings can serve as opportunities in which to screen and counsel women for IPV. Since our findings on the association between IPV and chronic physical illness are discrepant from the literature, further investigation is needed to elucidate the pathways between different forms of violence and risk of adverse health outcomes. This would be strengthened by population-based longitudinal studies, to gain a better understanding of the mechanisms underlying violence, lifestyle behaviours and physical illness.

The South African Stress and Health study was carried out in conjunction with the World Health Organization World Mental Health (WMH) Survey Initiative. We thank the WMH staff for assistance with instrumentation, fieldwork, and data analysis. These activities were supported by the United States National Institute of Mental Health (R01MH070884), the John D and Catherine T MacArthur Foundation, the Pfizer Foundation, the US Public Health Service (R13-MH066849, R01-MH069864 and R01 DA016558), the Fogarty International Center (FIRCA R01-TW006481), the Pan American Health Organization, Eli Lilly and Company, OrthoMcNeil Pharmaceutical, Inc., GlaxoSmithKline and Bristol-Myers Squibb. The South African Stress and Health study was funded by grant R01MH059575 from the National Institute of Mental Health and the National Institute of Drug Abuse with supplemental funding from the South African Department of Health and the University of Michigan. Dan Stein and Soraya Seedat are also supported by the Medical Research Council (MRC) of South Africa and the National Research Foundation (NRF). Soraya Seedat is supported by the South Africa Research Chairs Initiative of the Department of Science and Technology and National Research Foundation. Jesse Gass was supported by the Leitner Family Fellowship from the Institute of African Studies and the Mailman School of Public Health at Columbia University. A complete list of WMH publications can be found at http://www.hcp.med.harvard.edu/wmh/.

The authors thank Kathleen McGaffigan (Harvard University) for her assistance with the statistical analyses.

\section{References}

1. Heise L, Garcia-Moreno C. Violence by intimate partners. In: Krug EG, Dahlberg LL, Mercy JA, Zwi AB, Lozano R, eds. World Report on Violence and Health. Geneva: World Health Organization, 2002: 89-121.

2. Garcia-Moreno C, Jansen HAFM, Ellsberg M, Heise L, Watts CH. Prevalence of intimate partner violence: findings from the WHO multi-country study on women's health and domestic violence. Lancet 2006; 368: 1260-1269.

3. Bonomi AE, Anderson ML, Reid RJ, Rivara FP, Carrell D, Thompson RS. Medical and psychosocial diagnoses in women with a history of intimate partner violence. Arch Intern Med 2009; 169(18): 1692-1697.

4. Breiding MJ, Black MC, Ryan GW. Chronic disease and health risk behaviours associated with intimate partner violence - 18 US states/territories, 2005. Ann Epidemiol 2005; 18: 538-544.

5. Coker AL, Smith PH, Fadden MK. Intimate partner violence and disabilities among women attending family practice clinics. J Womens Health 2005; 14(9): 829-838.

6. El-Bassel N, Gilbert L, Witte S, et al. Intimate partner violence and substance abuse among minority women receiving care from an inner-city emergency department. Womens Health Issues 2003; 13: 16-22.

7. Gerber MR, Ganz ML, Lichter E, Williams CM, McCloskey LA. Adverse health behaviours and the detection of partner violence by clinicians. Arch Intern Med 2005; 165: 1016-1021.
8. Lemon SC, Verhoek-Oftedahl W, Donnelly EF. Preventive healthcare use, smoking, and alcohol use among Rhode Island women experiencing intimate partner violence. J Womens Health Gend Based Med 2002; 11(6): 555-562.

9. Kishor S, Johnson K. Profiling Domestic Violence: A Multi-Country Study. Calverton, MD: ORC MACRO, 2004.

10. Ellsberg M, Jansen HAFM, Heise L, Watts CH, Garcia-Moreno C. Intimate partner violence and women's physical and mental health in the WHO multi-country study on women's health and domestic violence: an observational study. Lancet 2008; 371: 1165-1172.

11. Seedat S, Stein DJ, Jackson PB, Heeringa SG, Williams DR, Myer L. Life stress and mental disorders in the South African Stress and Health Study. S Afr Med J 2009; 99(5): 375-382.

12. Gupta J, Silverman JG, Hemenway D, Acevedo-Garcia D, Stein DJ, Williams DR. Physical violence among intimate partners and related exposures to violence among South African men. CMAJ 2008; 179 (6): 535-541.

13. Abrahams N, Jewkes $\mathrm{R}$, Laubscher, Hoffman M. Intimate partner violence: prevalence and risk factors for men in Cape Town, South Africa. Violence Vict 2006; 21 (2): 247-264.

14. Dunkle K L, Jewkes R K, Brown HC, Gray G E, McIntryre J A, Harlow SD. Gender-based violence, relationship power, and risk of HIV infection in women attending antenatal clinics in South Africa. Lancet 2004; 363 (9419): 1415-1421.

15. Dunkle KL, Jewkes RK, Nduna M, et al. Perpetration of partner violence and HIV risk behaviour among young men in the rural Eastern Cape, South Africa. AIDS 2006; 20(16): 2107-2114.

16. Jewkes R, Levin J, Penn-Kekana L. Risk factors for domestic violence: findings from a South African cross-sectional study. Soc Sci Med 2002; 55 (9):1603-1617.

17. Williams S, Williams DR, Stein DJ, Seedat S, Jackson PB, Moomal H. Multiple traumatic events and psychological distress: the South Africa Stress and Health Study. J Trauma Stress 2007; 20 (5): 845-855.

18. Seedat M, Van Niekerk A, Jewkes R, Suffla S, Ratele K. Violence and injuries in South Africa: prioritizing an agenda for prevention. Lancet 2009; 374: 1011-1022.

19. Williams DR, Herman A, Kessler RC, et al. The South African Stress and Health Study: rationale and design. Metab Brain Dis 2004; 19(1/2): 135-147.

20. Williams DR, Herman A, Stein DJ, et al. Twelve-month mental disorders in South Africa: prevalence, service use and demographic correlates in the populationbased South African Stress and Health Study. Psych Med 2008; 38: 211-220.

21. Kessler RC, Uston TB. The World Mental Health (WMH) Survey Initiative version of the World Health Organization (WHO) Composite International Diagnostic Interview (CIDI). Int J Methods Psychiatr Res 2004; 13: 93-121.

22. Research Triangle Institute. SUDAAN Release 10.0. Research Triangle Park, North Carolina: Research Triangle Institute, 2008.

23. Stein DJ, Williams SL, Jackson PB, et al. Perpetration of gross human rights violations in South Africa: Association with psychiatric disorders. S Afr Med J 2009; 99(5): 390-395

24. Campbell JC. Health consequences of intimate partner violence. Lancet 2002 359: 1331-1336

25. Marais A, de Villiers PJ, Möller AT, Stein DJ. Domestic violence in patients visiting general practitioners - prevalence, phenomenology, and association with psychopathology. S Afr Med J 1999; 89(6): 635-640.

26. Straus MA. Cross-cultural reliability and validity of the Revised Conflict Tactics Scales: a study of university student dating couples in 17 nations. Cross-Cult Res 2004; 38: 407-432.

27. Straus MA, Hamby SL, Boney-McKoy S, Sugarman DB. The Revised Conflict Tactics Scales (CTS2). J Fam Issues 1996; 17: 283-316.

Accepted 7 June 1010. 